\title{
Impulsive Lifestyle Counselling Versus Treatment as Usual to Reduce Offending in People with Co- Occurring Antisocial Personality Disorder and Substance Use Disorder: A Post Hoc Analysis - BMC
}

Morten Hesse ( $\square$ mh.crf@psy.au.dk)

Aarhus University

Birgitte Thylstrup

Aarhus University

\section{Research Article}

Keywords: Antisocial personality disorders, substance use disorders, psycho-education, offending, register-based study

Posted Date: July 26th, 2021

DOI: https://doi.org/10.21203/rs.3.rs-534437/v1

License: (9) (1) This work is licensed under a Creative Commons Attribution 4.0 International License.

Read Full License 


\section{Abstract}

Objectives: To assess the impact of a psychoeducation for antisocial personality disorder on offending after randomization to treatment.

Design: Multicentre, superiority, non-blinded randomized controlled trial. Random assignment was conducted in blocks of varying sizes at a central randomization centre.

Setting: Nine outpatient uptake areas in Denmark.

Participants: One hundred and seventy six patients with antisocial personality disorder in treatment for substance use disorders were randomized to treatment as usual or ILC $(n=80 ; n=96)$. A total of 165 patients could be linked to criminal records collected between randomization and November $2019(n=91$; $n=74)$.

Intervention: The Impulsive Lifestyle Counselling program (ILC), is a brief psycho-educational program targeting antisocial behavior. The trial was conducted between January of 2012 and June 2014, and participants were tracked until December 2018, migration, or death, whichever occurred first.

Outcomes: Number of offences in the 12 months following trial randomization from official national registers.

Results: The mean number of offences was 2.76 in the TAU group (95\% Poisson confidence interval $[\mathrm{Cl}]=2.39,3.16)$ and 1.87 in the ILC group $(\mathrm{Cl}=0.97,1.43)$. Negative binomial regression was used to assess number of convictions within the first year; violent, property, driving under the influence, and drugrelated convictions. In both adjusted and unadjusted analyses, random assignment to ILC was associated with a lower number of total (incremental risk ration [IRR] $=0.43, p=.013$; adjusted IRR $=0.33$, $\mathrm{p}<.001$ ), violent (IRR=0.19, $\mathrm{p}=.001$; adjusted IRR=0.16, $\mathrm{p}=.018)$. Results were not significant for driving under the influence (unadjusted IRR=0.60, $p=.371$; adjusted IRR=0.87, $p=.521$ ), or drug offences (unadjusted IRR =1.06, $p=.905$; adjusted IRR=0.50, $p=.180$ ).

Conclusions: The ILC program shows promise in reducing offending behavior in people with comorbid substance use and antisocial personality disorder.

Trial registration: ISRCTN registry, ISRCTN67266318, 17/7/2012, https://doi.org/10.1186/ISRCTN67266318.

\section{Background}

Antisocial personality disorder (ASPD) is one of the most prevalent co-occurring disorders among people with substance use disorders (SUDs) $(1,2)$, and both are central to the externalizing spectrum of mental health problems (3). ASPD is strongly linked to association with deviant peers and traumatization (4), 
and offending $(5,6)$. While the condition often improves with time, many people continue to experience associated problems well into late adulthood and old age $(7,8)$.

Traditionally, people with ASPD have been described as 'treatment rejecting' (9), although much attention has been given to the importance of recognition and management of conduct disorders and antisocial behavior in children, young people, and adults (10-12). The few conducted treatment studies have generally included very few patients, but have shown promising results, underlining the fact that patients with a diagnosis of ASPD can be engaged in treatment. For example, in one of the studies, Davidson and colleagues offered cognitive-behavioral therapy to 52 men in a randomized trial in a community setting, and while the results were not statically significant, the authors noted that many of the patients at least received part of the treatment (13).

ASPD is often a complex condition and is highly comorbid, not just with SUDs, but also with other disorders such as anxiety and mood disorders (14). Recently, a study successfully tested mentalizationbased treatment as a treatment for patients with comorbid antisocial and borderline personality disorder (15) including a dynamic schedule of psychotherapy of 140 sessions of therapy, both group and individual. Findings from this study indicate that the treatment could reduce symptoms related to antisocial behavior including anger, hostility, and impulsivity. Furthermore, a study from Sweden 30 patients with borderline personality and antisocial behavior received Dialectical Behavior Therapy, another intensive long-term treatment (16) and found that the patients reduced a range of dysfunctional behaviors significantly during treatment, and the majority completed the treatment (16).

Despite the high prevalence of comorbid ASPD and SUD, few interventions have been designed to target this important comorbidity (2). Some evidence support that antisocial traits are linked to retention in treatment specifically among people with SUDs who are voluntarily in treatment $(17,18)$. In addition, ASPD is associated with offending after discharge from treatment for SUD $(5,19)$. The lack of research has been reflected in a recent Cochrane review that concluded that the few studies that exist do not support any psychological interventions for ASPD in general (20). One of the main criticisms raised in this review was the absence of data on convictions after treatment in existing literature. This is a valid criticism given that one of the criteria for ASPD is criminal behavior that could lead to convictions (21).

One of the few methods that have been tentatively tested is the Impulsive Lifestyle Counselling program (ILC). The ILC program aims to build self-understanding through psycho-education, thereby raising awareness of dysfunctional impulsive patterns of action related to ASPD (22). Impulsivity in the form of low self-control is especially important for understanding the link between ASPD and offending behavior(23). Thus, interventions targeting impulsive behaviors related to ASPD have the potential to motivate change in antisocial behavior, including aggression and offending behavior, as well as substance use (24).

In a pragmatic multicenter trial, ILC was added-on to treatment as usual (TAU) and tested in outpatient treatment for SUDs in Denmark. Random assignment to treatment $(n=176)$ was associated with lower risk of dropout from treatment (25), greater perceived help for ASPD (26), and more number of days 
abstinent at three months follow-up but not beyond (27). No effects were found on self-reported aggression.

The aim of the present study was to assess the impact of random assignment to ILC on offending behavior after treatment. Specifically, we aimed to test whether patients randomized to ILC offended less frequently than patients randomized to treatment as usual (TAU) up to one year after randomization.

\section{Methods}

\section{Design and settings}

A pragmatic randomized trial was conducted between January of 2012 and June 2014 in 13 sites in Denmark (27). Patients enrolled into free of charge community outpatient treatment services for people with SUDs were approached by the clinical staff and assessed using the ASPD module from the Mini International Neuropsychiatric Interview, version 5 (28).

Inclusion criteria were being between 18-65 years old, seeking or currently in treatment for a SUD; meeting lifetime and last year criteria for ASPD; and, able to provide informed consent. Exclusion criteria involved participating in group therapy with another patient in the trial; acute psychosis or severe brain damage; did not speak Danish; or, having plans that would interfere with study participation over the next three months.

\section{Participants}

In total, 176 patients were randomized in the trial, and of these 165 could be linked to the registers (93\%), ILC $(n=91 ;(54 \%)$ and TAU $(n=74 ; 44.9 \%)$. In all, 12.7 percent were women, the median age was 31.5 , and the interquartile range was $25.5-38$ years (Table 1$)$. Nearly half $(46.7 \%)$ were undergoing medicationassisted treatment for opioid dependence.

Diagnoses from the Danish Psychiatric Central Research Register are summarized in Table 1. All in all, 71 $(43 \%)$ had at least one of the diagnoses, and 34 had been in inpatient psychiatric care in the past ten years $(20.6 \%)$. The most common diagnoses were mood or anxiety diagnoses $(52,31.5 \%)$ followed by attention deficit/hyperactivity disorder (11, 6.7\%). No difference was found in terms of the presence of diagnoses between the TAU group $(n=35,47.3 \%)$, and the ILC group $\left(36,39.6 \%, \chi^{2}(1)=1.00, p=0.318\right)$

\section{Randomization}

Random assignment was conducted in blocks of varying sizes at the Centre for Alcohol and Drug Research, Aarhus University. Clinicians were informed of the results of the randomization only after baseline assessment had been completed.

\section{Interventions}

\section{Treatment as usual (TAU)}


Both treatment conditions had access to counselling and medication for drug use disorders in Denmark under the Act of Social Services $\S 101$, and for alcohol use disorders under the Healthcare Act $\S 141$. When patients were randomly assigned to the TAU condition, clinicians were explicitly asked to ensure that the patients got the highest level of possible care, based on mutual agreement between the counsellor and the patient.

\section{Impulsive Lifestyle Counselling (ILC)}

ILC is a six-session psycho-educational add-on module to usual care that focuses on raising awareness of maladaptive antisocial behaviors. The treatment has been elaborately discussed in previous papers (27) with the workbook made available online (29). In brief, the program encompasses sessions covering topics related to antisocial behavior and include; four areas of an "impulsive lifestyle"; the TriggersActions-Consequences Model, Streetwise Pride, Values that Break with the Impulsive Lifestyle; Social Networks, and Booster session).

\section{Data linkage}

In the spring of 2020, baseline data was linked with data from date of death, socio-demographic data, and criminal justice data on a protected Statistics Denmark server.

The Central Criminal Register was used to obtain information on convictions, and contains offenses and offenders in criminal cases for use in criminal procedures since 1978. The information is updated on a regular basis by the police districts in Denmark and the departments of the National Commissioner of Police (30).

The Danish Psychiatric Central Research Register was used to obtain information on psychiatric diagnoses given over a ten year period prior to randomization (31). The register contains dates of onset and end of any treatment and all diagnoses. While validation studies have been limited to specific diagnoses, the register is almost complete for hospital-based care, and thus most patients with moderate to severe mental health problems are likely to be included (31).

\section{Outcomes}

For this study, the outcomes were criminal offending occurring within one year of randomization, and leading to a conviction of guilty (i.e., not a warning or charges dropped). The date of crime was the date at which the police believed that the criminal activity was initiated according to the recorded charge(s). The primary outcome was the total number of crimes committed during the first year after study randomization. Secondary outcomes included number of types of offences in the register that could be directly linked to antisocial behavior: property offences, violent offences, drug-related offences (excluding simple possession of drugs for own use), and driving under the influence of alcohol and drugs (DUI). In order to avoid small cells in the analyses, violent offences included sexual offences and weapons offences, as they both involve aggressive behavior towards others (32). 
We considered only the first year after randomization, because this timeframe allowed enough time for the patients to offend, while not being so distant from the trial interventions that any effects would have been likely eroded by other interventions or life events (33).

\section{Control variables}

For all analyses, adjusted models were assessed including age, gender, and medication-assisted treatment for opioid use disorders at baseline, similar to previous reports from this trial (27). In addition, all analyses controlled for the same variable in the year leading up to randomization (e.g., for the total number of offences in the year after randomization, the adjusted analysis included the total number of offences in the year prior to randomization in the model).

In addition, we conducted sensitivity analyses controlling for the presence of severe mental illness, mood or anxiety disorder, attention deficit/hyperactivity disorder, or substance induced diagnoses. However, since none of these variables were associated with offending in univariate analyses, and since the results did not change after including them in the analysis, we do not report these analyses.

\section{Statistical Analyses}

Since the outcomes were all essentially count variables, we considered only count models for this study (i.e., Poisson, negative binomial, and zero-inflated models). To select the most parsimonious model, we relied on the Bayesian Information Criterion (BIC, 34). The BIC takes on lower values as the model becomes more parsimonious, taking both model fit and model complexity into consideration.

All analyses were conducted as intention-to-treat, i.e., patients were included in the group to which they were randomized regardless of the amount of treatment they actually received.

\section{Results}

During the follow-up, the patients committed 312 offences leading to convictions, corresponding to a mean of 1.89 offences per person (standard deviation $=6.26$ ). The mean number of offences in the TAU group was $2.76(95 \%$ Poisson confidence interval $[\mathrm{Cl}]=2.39,3.16)$, and in the ILC group the mean was $1.87(\mathrm{Cl}=0.97,1.43)$.

Patients are categorized by randomization in Table 2 according to three groups: (1) Patients who did not offend in the first year after randomization, patients who offended once or twice, and patients who offended three or more times by randomization status. A more fine-grained description by number of offences would violate rules against downloading micro-data from the Statistics Denmark Server. Marginally more patients randomized to the ILC condition were crime free $(63.7 \%)$, compared with the TAU condition (53.3\%), slightly more had offended one or two times $(26.4 \%$ vs. $20 \%)$, and fewer had offended three or more times ( $9.9 \%$ vs. $26.7 \%$ ). Note that this data is provided for information and should not be considered hypothesis testing in relation to this paper. 


\section{Model selection for number of offences leading to conviction}

According to the BIC, the best-fitting model was simple negative binomial regression for all outcomes in this study.

\section{Results of count regression models}

The results of the count variable regression are summarized in Table 3. Randomization to the ILC condition was associated with a lower number of total convictions, both in the unadjusted (IRR $=0.43, p=$ 0.013 ) and adjusted (adjusted IRR $=0.33, p=0.001$ ) models. Randomization to ILC was associated with a lower number of offences associated with violence, weapons, or sexual assaults (unadjusted IRR $=0.19$, $p=0.007$, adjusted IRR $=0.20, p=0.008$ ), property offences (unadjusted IRR $=0.30, p=0.003$, adjusted $I R R=0.42, p=0.010$ ). Results for driving under the influence of alcohol and drugs and drug offences were not significant (driving under the influence: unadjusted IRR $=0.49, p=0.371$, adjusted IRR $=0.60, p=$ 0.521 ; drug offences: unadjusted IRR $=1.06, p=0.905$; adjusted IRR $=0.50, p=0.180$ ).

\section{Discussion}

This is, to our knowledge, the first study to tentatively assess whether an intervention directed towards people with antisocial personality disorder would reduce offending (20). The results are promising, in that patients randomly assigned to the active intervention offended less than those assigned to treatment as usual, including the total number of offences, violent offences, and driving under the influence. However, the results were not robust for property offences, and no difference was observed for drug-related crime. The lack of results within these two offending categories may partly be related to the fact that they are less related to impulsive behavior and decrease in substance use $(35,36)$. On the other hand, acts of violence are strongly linked to ASPD and antisocial personality traits $(37,38)$, as is driving under the influence (39).

The findings were based on community-based substance abuse treatment, and may not generalize to other important settings for patients with co-morbid ASPD and substance use such as prison-based treatment (40), or residential rehabilitation (41). Further research is needed to assess the best ways to treat patients with co-morbid ASPD and substance use in these settings.

Two control variables predicted offending after randomization; a history of previous offending in the year leading up to randomization predicted a higher risk of offending, and medication-assisted treatment predicted a lower risk of offending. Previous offending is robustly associated with new offending in scientific literature (42). In this sample, medication-assisted treatment was available to those who were opioid dependent, thus the findings have no bearing on whether medication-assisted treatment would be associated with lower risk of offending. However, future studies should involve and compare patient groups with and without non-opioid use disorders (43). 
The group of patients in this study had a high prevalence of comorbid mental health conditions prior to randomization, with nearly half diagnosed in a psychiatric setting in the ten years prior to randomization. This is to be expected in a group of patients with comorbid ASPD and SUD, where both of these conditions typically have a high burden of comorbidity. We did not find that other comorbid conditions had a significant impact on offending in this sample, or that the results of the intervention was affected by comorbidity status.

The greatest strength of this study is the longitudinal before-after design, which offers a unique opportunity to study reported criminal offences up to one year from study intake. However, some limitations must be noted. As with any register-based study, we were not able to provide direct quality control over the process of data collection. Secondly, we were only able to include reported offences, and it is highly likely that other offences have been committed in the same time-period (e.g. drug sale). Thus, the study provides a conservative estimate of offences committed. However, as this is the case for both trial groups, it is very unlikely that it has changed the difference in effect between groups.

\section{Conclusions}

The short-term ILC program targeting impulsive behavior and criminal offending has the potential to reduce offending behavior among people with antisocial personality disorder.

\section{Abbreviations}

ASPD

Antisocial personality disorder.

ILC

Impulsive Lifestyle Counselling.

IRR

Incremental Risk Ratio.

SUD

Substance use disorder.

TAU

Treatment as usual.

\section{Declarations}

\section{Ethics approval and consent to participate}

The present project was reviewed by the regional ethics committee of the Capital Region of Denmark and deemed exempt from a formal evaluation (J\#H-3-2012-FSP45). The committee concluded that at the time of trial review, the study did not require a full ethical evaluation. All participants provided a written and verbal consent prior to completing intake assessment detailing the nature of the trial and the 
possibility of later data linkage. Data are stored on secure servers at Statistics Denmark and procedures approved by the Danish Data Protection Agency.

The study was carried out in accordance with the Declaration of Helsinki (44).

\section{Consent for publication}

Not applicable, since individual data are not reported in this manuscript.

\section{Availability of data and materials}

Due to the Danish Data Protection legislation, raw data that constitutes sensitive data on individuals, including data that has been pseudonymized (i.e., personal data in such a manner that the personal data can no longer be attributed to a specific data subject without the use of additional information) cannot be submitted in full. Further please note, that all data are stored on servers at Statistics Denmark, and can in any event be accessed only by specific approval by Statistics Denmark at its sole discretion. Access to the data can be obtained by application to Statistics Denmark at dst.dk, and the authors will assist anybody wishing to apply for access to the data.

\section{Competing interests}

The authors declare that they have no competing interests in relation to this manuscript.

\section{Funding}

This study was supported by an unnumbered grant from Trygfonden (trygfonden.dk).

\section{Authors' contributions}

Both authors collaborated to conduct the literature review and in conceiving of the study, and designed and planned the original study in collaboration. $\mathrm{MH}$ conducted the statistical analysis and data linkage. Both author drafted sections of the manuscript, and both authors reviewed and approved of the final manuscript.

\section{References}

1. Goldstein RB, Chou SP, Saha TD, Smith SM, Jung JS, Zhang HT, et al. The Epidemiology of Antisocial Behavioral Syndromes in Adulthood: Results From the National Epidemiologic Survey on Alcohol and Related Conditions-III. J Clin Psychiat. 2017;78(1):90-8.

2. Fraser R, Isaif L, Teles D, Laporte L. Personality Disorders and Addiction Disorders. In: el-Guebaly N, Carrà G, Galanter M, Baldacchino AM, editors. Textbook of Addiction Treatment: International Perspectives. Cham: Springer International Publishing; 2021. p. 1373-89. 
3. Caspi A, Houts RM, Belsky DW, Goldman-Mellor SJ, Harrington H, Israel S, et al. The p Factor: One General Psychopathology Factor in the Structure of Psychiatric Disorders? Clin Psychol Sci. 2014;2(2):119-37.

4. Wojciechowski TW. Post-traumatic stress disorder and having antisocial peers in adolescence are risk factors for the development of antisocial personality disorder. Psychiat Res. 2019;274:263-8.

5. Fridell M, Hesse M, Jaeger MM, Kuhlhorn E. Antisocial personality disorder as a predictor of criminal behaviour in a longitudinal study of a cohort of abusers of several classes of drugs: Relation to type of substance and type of crime. Addict Behav. 2008;33(6):799-811.

6. Yu RQ, Geddes JR, Fazel S. Personality Disorders, Violence, and Antisocial Behavior: A Systematic Review and Meta-Regression Analysis. J Pers Disord. 2012;26(5):775-92.

7. Black DW. The Natural History of Antisocial Personality Disorder. Can J Psychiat. 2015;60(7):30914.

8. Moffitt TE. Male antisocial behaviour in adolescence and beyond. Nat Hum Behav. 2018;2(3):17786.

9. Tyrer P, Mitchard S, Methuen C, Ranger M. Treatment rejecting and treatment seeking personality disorders: Type R and Type S. J Pers Disord. 2003;17(3):263-8.

10. NICE guidelines. Antisocial behaviour and conduct disorders in children and young people: recognition and management National Institute for Health and Care Excellence; 2013 [updated 19-042017.

11. NICE pathways. Antisocial behaviour and conduct disorders in children and young people overview children and young people overview 2020 [

12. NICE guidelines. Antisocial personality disorder: prevention and management 2013 [updated 03-272013.

13. Davidson K, Halford J, Kirkwood L, Newton-Howes G, Sharp M, Tata P. CBT for violent men with antisocial personality disorder. Reflections on the experience of carrying out therapy in MASCOT, a pilot randomized controlled trial. Personal Ment Health. 2010;4(2):86-95.

14. Werner KB, Few LR, Bucholz KK. Epidemiology, Comorbidity, and Behavioral Genetics of Antisocial Personality Disorder and Psychopathy. Psychiat Ann. 2015;45(4):195-9.

15. Bateman A, O'Connell J, Lorenzini N, Gardner T, Fonagy P. A randomised controlled trial of mentalization-based treatment versus structured clinical management for patients with comorbid borderline personality disorder and antisocial personality disorder. Bmc Psychiatry. 2016;16.

16. Wetterborg D, Dehlbom P, Langstrom N, Andersson G, Fruzzetti AE, Enebrink P. Dialectical Behavior Therapy for Men with Borderline Personality Disorder and Antisocial Behavior: A Clinical Trial. J Pers Disord. 2020;34(1):22-39.

17. Daughters SB, Stipelman BA, Sargeant MN, Schuster R, Bornovalova MA, Lejuez CW. The interactive effects of antisocial personality disorder and court-mandated status on substance abuse treatment dropout. J Subst Abuse Treat. 2008;34(2):157-64. 
18. Ohlin L, Hesse M, Fridell M, Tatting P. Poly-substance use and antisocial personality traits at admission predict cumulative retention in a buprenorphine programme with mandatory work and high compliance profile. Bmc Psychiatry. 2011;11:81.

19. Jansson I, Hesse M, Fridell M. Influence of Personality Disorder Features on Social Functioning in Substance-Abusing Women Five Years after Compulsive Residential Treatment. European Addiction Research. 2009;15(1):25-31.

20. Gibbon S, Khalifa NR, Cheung NH, Vollm BA, McCarthy L. Psychological interventions for antisocial personality disorder. Cochrane Database of Systematic Reviews. 2020;9:CD007668.

21. American Psychiatric Association. DSM-5. In: Diagnostic and statistical manual of mental disorders teD-, editor. Arlington: American Psychiatric Association; 2013.

22. Hesse $M$, Thylstrup $B$. Reaching out to patients with antisocial personality disorder in substance use disorder treatment: interactions between counsellors and clients in a psycho-educational intervention.. Advances in Dual Diagnosis. 2016;9(2/3):97-107.

23. Wojciechowski TW. The Relevance of Hostility and Self-Control as Mediators of the Relationship Between Antisocial Personality Disorder and Offending. Crime \& Delinquency. 2020.

24. Vassileva J, Conrod PJ. Impulsivities and addictions: a multidimensional integrative framework informing assessment and interventions for substance use disorders. Philos T R Soc B. 2019;374(1766).

25. Thylstrup B, Hesse M. Impulsive lifestyle counseling to prevent dropout from treatment for substance use disorders in people with antisocial personality disorder: A randomized study. Addict Behav. 2016;57:48-54.

26. Thylstrup B, Schroder S, Fridell M, Hesse M. Did you get any help? A post-hoc secondary analysis of a randomized controlled trial of psychoeducation for patients with antisocial personality disorder in outpatient substance abuse treatment programs. Bmc Psychiatry. 2017;17.

27. Thylstrup B, Schroder S, Hesse M. Psycho-education for substance use and antisocial personality disorder: a randomized trial. Bmc Psychiatry. 2015;15.

28. Sheehan DV, Janavs J, Baker R, Harnett-Sheehan K, Knapp E, Sheehan M, et al. MINI - Mini International Neuropsychiatric Interview - English Version 5.0.0 - DSM-IV. J Clin Psychiat. 1998;59:34-57.

29. Hesse M, Thylstrup B. Manual for Impulsive Lifestyle Counselling. 2017.

30. Lund J. Mentally retarded criminal offenders in Denmark. Br J Psychiatry. 1990;156:726-31.

31. Mors O, Perto GP, Mortensen PB. The Danish Psychiatric Central Research Register. Scand J Public Healt. 2011;39:54-7.

32. Polaschek DLL. The psychology of violent offending. In: Polaschek DLL, Day A, Hollin CR, editors. The Wiley International Handbook of Correctional Psychology: Wiley-Blackwell 2019.

33. Herbert RD, Kasza J, Bo K. Analysis of randomised trials with long-term follow-up. Bmc Med Res Methodol. 2018;18. 
34. Schwarz GE. Estimating the dimension of a model. Annals of Statistics. 1978;6(2):461-4.

35. Pardini DA, Byrd AL, Hawes SW, Docherty M. Unique Dispositional Precursors to Early-Onset Conduct Problems and Criminal Offending in Adulthood. Journal of the American Academy of Child and Adolescent Psychiatry. 2018;57(8):583 - 92.e3.

36. Vaughn MG, Salas-Wright CP, Reingle-Gonzalez JM. Addiction and crime: The importance of asymmetry in offending and the life-course. J Addict Dis. 2016;35(4):213-7.

37. Kolla NJ, Meyer JH, Bagby RM, Brijmohan A. Trait Anger, Physical Aggression, and Violent Offending in Antisocial and Borderline Personality Disorders. J Forensic Sci. 2017;62(1):137-41.

38. Azevedo J, Vieira-Coelho M, Castelo-Branco M, Coelho R, Figueiredo-Braga M. Impulsive and premeditated aggression in male offenders with antisocial personality disorder. Plos One. 2020;15(3).

39. Luk JW, Worley MJ, Winiger E, Trim RS, Hopfer CJ, Hewitt JK, et al. Risky driving and sexual behaviors as developmental outcomes of co-occurring substance use and antisocial behavior. Drug Alcohol Depen. 2016;169:19-25.

40. de Andrade D, Ritchie J, Rowlands M, Mann E, Hides L. Substance Use and Recidivism Outcomes for Prison-Based Drug and Alcohol Interventions. Epidemiol Rev. 2018;40(1):121-33.

41. Hides L, Quinn C, Stoyanov S, Kavanagh D, Baker A. Psychological interventions for co-occurring depression and substance use disorders. Cochrane Database of Systematic Reviews. 2019(11).

42. Sedgwick O, Young S, Das M, Kumari V. Objective predictors of outcome in forensic mental health services-a systematic review. CNS Spectr. 2016;21(6):430-44.

43. Hesse M, Thylstrup B, Karsberg SH, Pedersen MM, Pedersen MU. ILC-OPI: impulsive lifestyle counselling versus cognitive behavioral therapy to improve retention of patients with opioid use disorders and externalizing behavior: study protocol for a multicenter, randomized, controlled, superiority trial. Bmc Psychiatry. 2021;21(1):183.

44. Hellmann F, Verdi M, Schlemper BR, Caponi S. 50th Anniversary of the Declaration of Helsinki: The Double Standard Was Introduced. Arch Med Res. 2014;45(7):600-1.

\section{Tables}

Table 1. Baseline statistics $(\mathrm{N}=165)$ 


\begin{tabular}{|c|c|c|c|}
\hline Variable & & Observations & Percentage \\
\hline TAU & & 74 & $44.9 \%$ \\
\hline ILC & & 91 & $51.1 \%$ \\
\hline Female gender & & 21 & $12.7 \%$ \\
\hline \multirow[t]{2}{*}{ Male gender } & & 144 & $87.3 \%$ \\
\hline & & Median & $\begin{array}{l}\text { Inter- } \\
\text { quartile } \\
\text { range }\end{array}$ \\
\hline Age & & 31.5 & 12.4 \\
\hline Medication-assisted at baseline & & 77 & $46.7 \%$ \\
\hline Psychiatric history (past ten years) & $\begin{array}{l}\text { ICD-10 Diagnostic } \\
\text { codes }\end{array}$ & & \\
\hline $\begin{array}{l}\text { Severe mental illness (schizophrenia spectrum or } \\
\text { bipolar disorder) }\end{array}$ & F2X, F30X, F31X & 9 & $5.5 \%$ \\
\hline Mood or anxiety disorder & F32X-F399, F4X & 52 & $31.5 \%$ \\
\hline Attention deficit hyperactivity disorder & F900 & 11 & $6.7 \%$ \\
\hline Substance induced psychosis & F1X5 & 8 & $4.9 \%$ \\
\hline Any psychiatric diagnosis[1] & & 71 & $43.0 \%$ \\
\hline Any inpatient care & & 34 & $20.6 \%$ \\
\hline
\end{tabular}

[1] Includes all diagnoses listed above.

Table 2. Proportion with convictions by randomization status $(n=165)$

\begin{tabular}{|lllll|}
\hline & TAU (n=74) & \multicolumn{3}{c|}{ ILC (n=91) } \\
\hline None & 39 & $52.7 \%$ & 58 & $63.7 \%$ \\
\hline One or two & 15 & $20.3 \%$ & 24 & $26.4 \%$ \\
\hline Three or more & 20 & $27.0 \%$ & 9 & $9.9 \%$ \\
\hline
\end{tabular}

Table 3. Coefficients for all criminal justice outcomes (negative binomial regression) 


\begin{tabular}{|c|c|c|c|c|c|c|}
\hline & $\begin{array}{l}\text { Unadjusted } \\
\text { IRR[2] }\end{array}$ & $\begin{array}{l}95 \% \\
\mathrm{CI}[3]\end{array}$ & $\begin{array}{l}\mathrm{P}- \\
\text { value }\end{array}$ & $\begin{array}{l}\text { Adjusted } \\
\text { IRR[4] }\end{array}$ & Interval & $\begin{array}{l}\mathrm{P} \text { - } \\
\text { value }\end{array}$ \\
\hline Total convictions & 0.43 & $\begin{array}{l}0.22- \\
0.83\end{array}$ & .013 & 0.33 & $\begin{array}{l}0.18- \\
0.62\end{array}$ & $<.001$ \\
\hline Property & 0.30 & $\begin{array}{l}0.14- \\
0.66\end{array}$ & .003 & 0.42 & $\begin{array}{l}0.21- \\
0.81\end{array}$ & .010 \\
\hline Violence & 0.19 & $\begin{array}{l}0.06- \\
0.64\end{array}$ & .007 & 0.20 & $\begin{array}{l}0.06- \\
0.65\end{array}$ & .008 \\
\hline Drug offences & 1.06 & $\begin{array}{l}0.38- \\
2.97\end{array}$ & .905 & 0.50 & $\begin{array}{l}0.18- \\
1.38\end{array}$ & .180 \\
\hline $\begin{array}{l}\text { Driving under the influence of } \\
\text { alcohol and drugs }\end{array}$ & 0.49 & $\begin{array}{l}0.10- \\
2.34\end{array}$ & .371 & 0.60 & $\begin{array}{l}0.12- \\
2.87\end{array}$ & .521 \\
\hline
\end{tabular}

[2] Incremental risk ratio.

[3] Confidence interval

[4] Adjusted incremental risk ratio. Adjusted models were adjusted for age, gender, substitution treatment at baseline, and the number of offences of the same type in the year prior to randomization.

\section{Supplementary Files}

This is a list of supplementary files associated with this preprint. Click to download.

- CONSORTExtensionforPragmaticTrialsChecklist.docx 